\title{
Evaluation of the Performance Level of Water Distribution Systems under Normal and Abnormal Operating Conditions
}

\author{
Ahmed M. Abou Elmagd ${ }^{1 *}$, Wail A. Fahmy ${ }^{2}$, Marwa A. Diab ${ }^{3}$ \\ ${ }^{1,3}$ Department of Civil Engineering, Sanitary and Environmental Engineering, Faculty of Engineering at Shoubra, Benha University, Egypt. \\ ${ }^{2}$ Department of Civil Engineering, Irrigation \& Drainage Engineering Faculty of Engineering -Shoubra, Benha University, Egypt
}

Correspondence Author: Ahmed M. Abou Elmagd, Assistant Professor of Sanitary and Environmental Engineering, Faculty of Engineering at Shoubra, Benha University, Egypt

E-mail: - ahmed.mahmoud@feng.bu.edu.eg; ahmedcivil2003@yahoo.com

Received date: 11 August. 2019, Accepted date: 11 Nov. 2019, Online date: 1 December 2019

Copyright: (C) Ahmed M. Abou Elmagd et al, This is an open-access article distributed under the terms of the Creative Commons Attribution License, which permits unrestricted use, distribution, and reproduction in any medium, provided the original author and source are credited.

\begin{abstract}
Designers produce several designs for the same water distribution system. The designers are interested in finding the appropriate pipe sizes, while the contractors are interested in reducing the cost, without any rules that can govern the choice. This study sets three rules or indices to measure network performance. To reduce water losses under normal operating conditions, the Efficiency index was adopted. To express the network's ability to deliver the required water under abnormal operating conditions, the Adequacy index was used, while the Equity Index represents the fairness of the distribution of that water shortage. Then, the fuzzy set approach is applied to combine them into an Overall Design Performance Index (ODPI). The procedure is applied on twenty alternate designs for a certain system all of them achieve $30 \mathrm{mH} 20$ at the furthest point. The maximum adequacy would correspond to more uniform water distribution and a higher water leakage. It is also found that the more number of paths, total paths' lengths and number of pipes, the more are the adequacy and the equity and the worse is the efficiency. The findings showed that ODPI and cost are directly proportional to the adequacy and equity aspect, while inversely proportion to efficiency.
\end{abstract}

Keywords: Water distribution system - performance evaluation - performance indices - segment isolation - pressure-dependent demand analysis- fuzzy set approach.

\section{INTRODUCTION}

Water Distribution System (WDS) is one of the most substantial components of a water supply utility, devoted mainly to convey water from treatment plants to consumers' taps. These infrastructures with its pipes, pumps, valves, storage tanks, and other hydraulic elements expend massive expenditures, nearly estimated as $80 \%$ to $85 \%$ of the total supply system cost [1]. Therefore, there is a need that a WDS design achieves a higher performance level to guarantee a better-quality service to people and at the same time, cutting down the incurred costs. Generally, a WDS under normal operating conditions should be able to provide all consumption demands with required pressures and without leakage or interruptions. However, sometimes failure of certain parts might occur, and the system is required to run during these problems. These abnormal conditions lead to pressure deficiency and subsequently, insufficient water supply.

In the literature, there are several studies conducted to estimate the performance of a WDS. But, the evaluation is accomplished concerning one or multi-aspects (e.g. quantity/quality of delivered water, water leakage) separately without considering the interdependency between these aspects[2]. Gheisi and Naser [3] studied the performance response of a WDS in three issues simultaneously. However, one concern related to these studies describes the distribution system's performance in case of pressure deficiency, overlooking the ordinary running state. The reason might be that specifications guaranteed the achievement of functional requirements if the standard of minimum pressure is met [4].

Moreover, current performance analysis techniques apply different patterns to simulate a failure in the system (e.g. node isolation [2], pipe failure [3], or assumed arbitrary problems [5]. But in real applications, the water network is divided into a group of segments where the "segment" can be defined as the smallest part of the distribution network can be isolated by valves [6]. And 
when a particular failure occurs, isolation valves are utilized to take the whole defected segment out of service for maintenance or repair.

This research proposes a new methodology to comprehensively assess the performance of a WDS through three indices considering both normal and abnormal conditions and employing the concept of segment isolation. The values of the indicators are then combined into one single number that expresses the overall system performance. To illustrate the procedure, the method is applied on twenty alternate designs for a certain distribution system followed by a discussion of the output results. Finally, conclusions are found.

\section{PROPOSED PERFORMANCE EVALUATION METHODOLOGY}

The aim of performance assessment is to achieve functional distribution systems by giving relevant feedback to management. As such, it may assist decision-makers to design a system with satisfactory performance under different operating conditions [7]. Regarding the proposed evaluation method, it is based on three performance indices. Each of them provides a quantitative measure of a particular characteristic of the water distribution system. The first index, the efficiency, is calculated during normal conditions while the other two indices, the adequacy and the equity, are determined under abnormal conditions. Using the fuzzy set approach, the values of the three indices are coupled together into one overall index representing the performance level of a system.

\section{Efficiency Performance Index (PI $\left.{ }^{\text {eff }}\right)$}

Amount of leakage water becomes critical issues for instance, rates up to $50 \%$ have been quoted in some aging urban networks [8]. The available pressure inside the pipes controls about 5\%-55\% of this leakage [9]. Moreover, about two to three percent of the world energy is consumed in water supply, [10]. Hence, leakage is a vital factor to consider in rating the performance of a water network system, where it causes loss of water, energy and money. Leakage has checked under normal operating condition, where, the maximum possible leak can be expected due to maximum available pressure. In general, the amount of water leaked from a pipe, $Q_{p}^{\text {Leak }}(\mathrm{L} / \mathrm{s})$, is commonly estimated by Germanopoulos Technique, for its simplicity, as follows [11]:

$$
Q_{p}^{\text {Leak }}=C L_{p}\left(P_{p}^{a v e}\right)^{1.18}
$$

Where $L_{p}$ is the length of the pipe in meter $(\mathrm{m})$ and $P_{p}{ }^{a v e}$ is the average pressure occurred along the length of the pipe (m $\mathrm{H}_{2} \mathrm{O}$ ). The subscript " $p$ " represents the pipe number. To include pipe material, pipe edge and no of nodes, coefficient $c$ has been used. In this study, C was taken as 0.0001 according to Gheisi and Naser, 2015 [3], and it is determined according to pipe properties. Bertola and Nicolini, 2006 [12] used "The Efficiency Performance Index" ( $\left.P I^{\text {eff }}\right)$ to express the percentage of actual water supplied to the supplied water plus the leaked water from the pipes.

$$
P I^{e f f}=\frac{\sum_{n=1}^{N} Q_{n}^{\text {sup }}}{\sum_{n=1}^{N} Q_{n}^{\text {sup }}+\sum_{p=1}^{P} Q_{p}^{\text {leak }}}
$$

Where $Q_{n}{ }^{\text {sup }}$ is the supplied water discharge $(\mathrm{L} / \mathrm{s})$ at node number $(\mathrm{n}), \mathrm{N}$ is the total number of nodes and $\mathrm{P}$ is the total number of pipes.

\section{Adequacy Performance Index $\left(\boldsymbol{P I}^{\text {ad }}\right)$}

This indicator is computed during the abnormal state to measure to what extent the quantity of water provided suffice for the users' requirements i.e. the capacity of water supply to meet the desired demand during segments isolation which represents the abnormal condition. Its value would give a picture on the response of a distribution system to failures and on how the final users would be influenced. For a certain noden, $P I^{\text {ad }}$ is defined as the ratio of the actual supplied water, $Q_{n}^{\text {sup }}$ (L/s), to the required water demand, $Q_{n}^{r e q}(\mathrm{~L} / \mathrm{s})$ "supply ratio" [13]. Regarding the whole system, the adequacy index of water delivery is determined while applying the segment isolation approach such that all segments are separated, one at a time. During each incident, the sum of supplied and required discharges at all nodes is calculated. Then, $P I^{\text {ad }}$ is found as:

$$
P I^{a d}=\frac{\sum_{S=1}^{S}\left[\sum_{n=1}^{N} Q_{n}^{s u p}\right]}{\sum_{S=1}^{S}\left[\sum_{n=1}^{N} Q_{n}^{r e q}\right]}
$$

Where: $S$ and $s$ are the number of segments in the WDN and the segment number, respectively.

\section{Equity Performance Index $\left(\boldsymbol{P I}^{e q}\right)$}

The adequacy index is not enough to judge the performance of WDN at an abnormal state. It is better to take in mind also how uniformly and equally the water shortage is shared among different users. After determining the supply ratio at each node in the network, it becomes easy to calculate the Equity index $\left(\mathrm{PI}^{\mathrm{eq}}\right)$ which used to express the performance considering the deviation of the adequacy of water delivery among WDN [14]:

$$
P I^{e q}=1-\frac{\sum \text { deviations of supply ratios }}{\sum \text { supply ratios }}
$$

Again, to simulate the real behavior, the method of segment isolation is applied and equation (4) turns to be: 


$$
P I^{e q}=1-\left[\frac{\sum_{s=1}^{S}\left[\sum_{n=1}^{N}\left|P I_{n}^{a d}-\frac{1}{N} \sum_{s=1}^{S}\left[\sum_{n=1}^{N} P I_{n}^{a d}\right]\right|\right]}{\sum_{S=1}^{S}\left[\sum_{n=1}^{N} P I_{n}^{a d}\right]}\right]
$$

\section{Implementation of the fuzzy approach set (FSA) and estimation of ODPI}

After determining the values of efficiency, adequacy, and equity for a network, the fuzzy set theory is applied to combine the three indices together to obtain an Overall Design Performance Index (ODPI) which expresses the total performance level of a

WDS. This technique is used as it is an effective way to consider the uncertainty in the evaluation medium [15]. The circumstances surrounding the design and operation stages of a WDS result in uncertain data to determine the exact level of performance. Also, there is no pre-defined threshold limit to judge the final performance as accepted or refused. The fuzzy set approach consists of three steps: fuzzification, aggregation and defuzzification as shown in Figure 1.

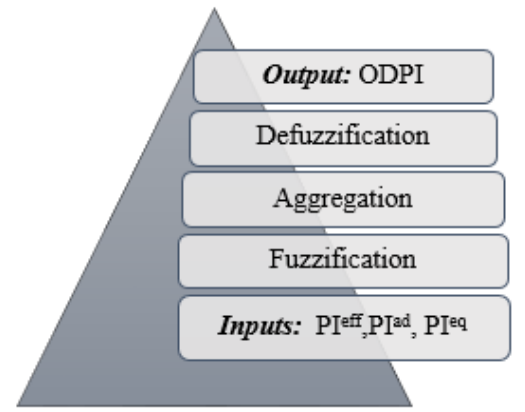

Fig.1: Flow chart of fuzzy set approach

\section{Fuzzification}

In the fuzzification stage, each input of the three performance indices is expressed as a group of linguistic variables. Therefore, it provides an alternative to describe and approximates the reasoning of the decision-making problems [16]. However, for an absolute the number of classes should be limited to less than seven. [17]. In this study, the PIs have five linguistic variables, namely, very low, low, satisfactory, competent, and excellent. The linguistic variable is defined by membership function (MF) which means that every PI has five MFs. The common MFs in practice are triangles, trapezoids, bell curves, Gaussian, and sigmoid functions. In this study, two simple computation function was applied, triangular and trapezoidal as shown in Figure 2.
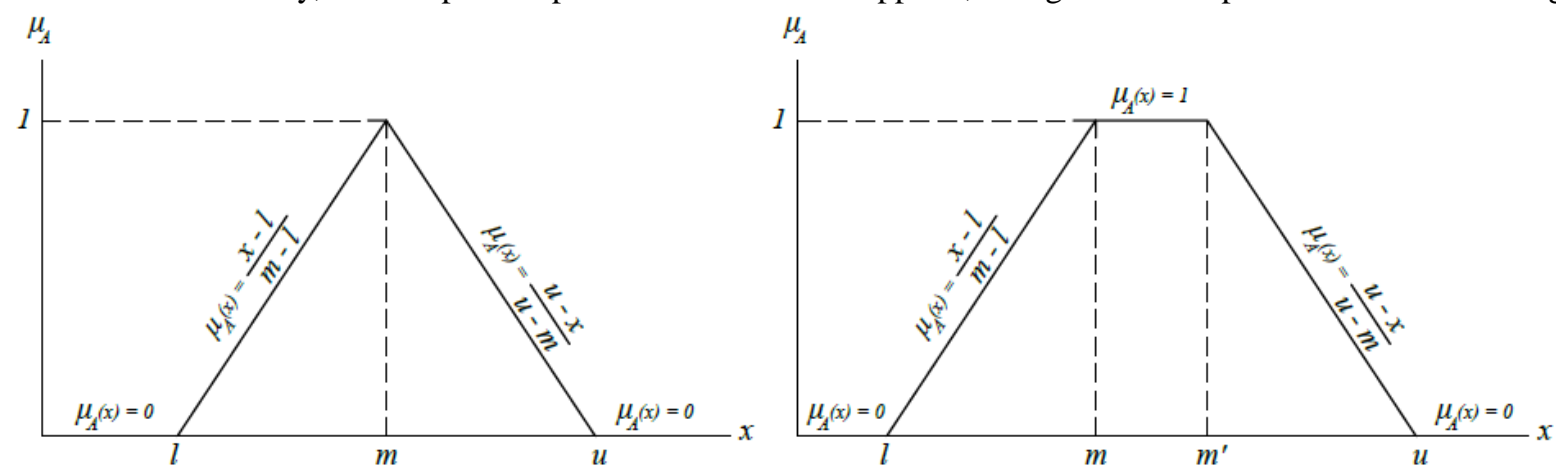

Fig. 2: Forms of triangular and trapezoidal MFs.

MF requires three parameters, the smallest possible value (1), most promising value $(\mathrm{m})$, and the largest possible value (u) that describe a fuzzy event [18]. Each triangular fuzzy number has linear representations on its left and right side. The trapezoidal MF requires four parameters $\left(l, m, m^{\prime}, u\right) . x$ is the value of PI between zero to one. The value of $\mu_{A}(x)$ is the result of the MF of each variable which can be calculated by the substitutes in equation (6) for triangular or equation (7) for trapezoidal [2].

$$
\mu_{A}(x)=\left\{\begin{array}{ll}
0 & \text { if } x<l, \\
\left(\frac{x-l}{m-l}\right) & \text { if } l \leq x \leq m, \\
\left(\frac{u-x}{u-m}\right) & \text { if } m \leq x \leq u, \\
0 & \text { if } x>u .
\end{array} \quad \text { (6) } \quad \mu_{A}(x)= \begin{cases}0 & \text { if } \quad x<l, \\
\left(\frac{x-l}{m-l}\right) & \text { if } \quad l \leq x \leq m, \\
1 & \text { if } m<x<m^{\prime}, \\
\left(\frac{u-x}{u-m^{\prime}}\right) & \text { if } m^{\prime} \leq x \leq u, \\
0 & \text { if } x>u .\end{cases}\right.
$$

In this research, the membership functions of each PI (efficiency, adequacy or equity) are the same with the parameters as illustrated in Figure 3. Noting that, for the "Very low" and "Excellent" categories, MFs are trapezoidal while they are triangular for other categories. 


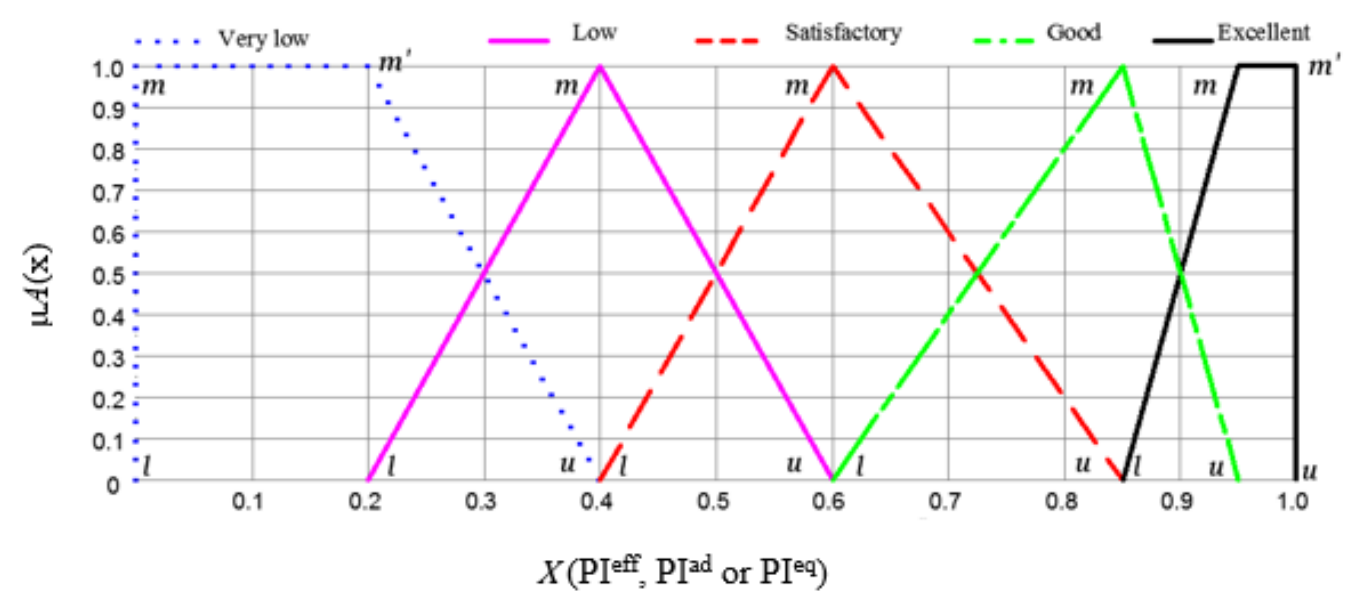

Fig. 3: The membership functions for the linguistic variables of PIs.

Finally, the fuzzification matrix $[F]$ can be estimated by knowing the values of PIs and their MFs.

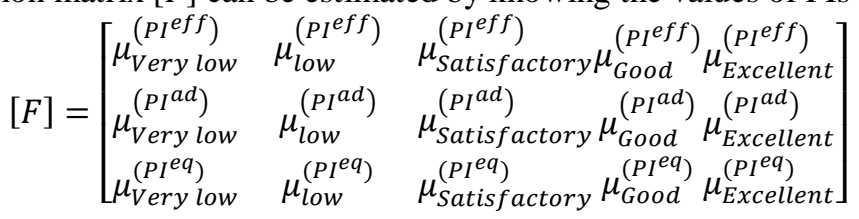

\section{Aggregation}

The second step in the procedure is the aggregation of the fuzzified values of the indices. It starts by assigning a weight to each input $W_{P I}$. Weight values reflect the risk level associated with a certain aspect of the system. In fact, it is not a direct task, such judgment can be made with a solid knowledge of the network and on the basis of the experts' opinions [5]. In this study, the significance of the indices is considered to be equal i.e. $W_{P I}$ of each index is one-third. The result of this aggregation is the fuzzified $O D P I\left(O D P I^{F}\right)$ and is obtained as:

\section{Defuzzification}

$$
\begin{aligned}
& {\left[O D P I^{F}\right]=\left[W_{P I}\right] *[F]=\left[\begin{array}{lll}
W_{P I}^{\text {eff }} & W_{P I}^{\text {ad }} & W_{P I}^{\text {eq }}
\end{array}\right] *[F]} \\
& {\left[O D P I^{F}\right]=\left[\begin{array}{llll}
O D P I_{\text {Very low }}^{F} & O D P I_{\text {low }}^{F} & O D P I_{\text {Satisfactory }}^{F} & \\
{\left[O D P I_{\text {Good }}^{F}\right.} & O D P I_{\text {Excellent }}^{F}
\end{array}\right]}
\end{aligned}
$$

The last step in the procedure is defuzzification (opposite of fuzzification) in which the representative value of the fuzzy set output is determined. Defuzzification is performed using the centroid method, starting with establishing the general scale that depicts the condition of ODPI (Equation 11). This scale aids the management to make an informed decision regarding a WDS [2]. The scale ranges from 0 (the lowest performance) to 1 (the highest performance) and is divided into five granularity levels as shown in Figure 4.

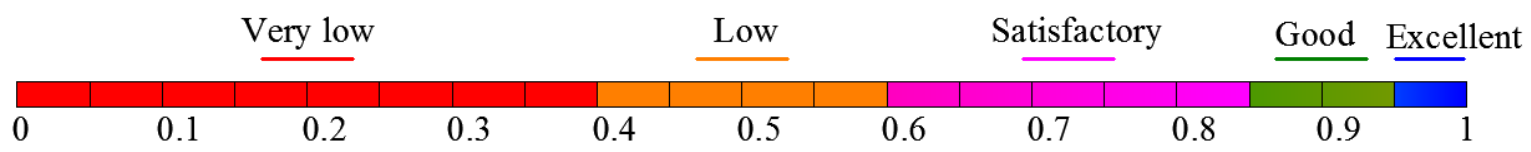

Fig. 4: Granularity levels of $O D P I$

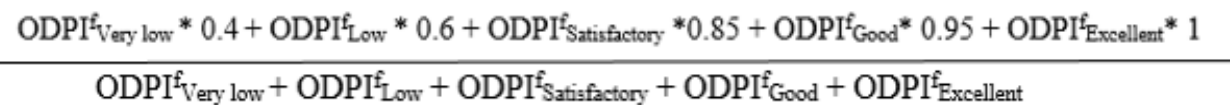

\section{Flowchart of the Methodology}

The whole evaluation process is illustrated by a flowchart form displayed in Figure 5. This chart indicates the involved steps to calculate the $O P D I$ for a WDS, beginning with creating a computer model for the system to do a hydraulic analysis during different operating conditions. The distribution network is divided into segments based on the assigned locations of the isolation valves. The efficiency index is calculated in case pressures and discharges are enough to deliver all nodal demands to all parts of the system without any isolated parts. In case of failures, the adequacy and equity indices are calculated as stated in 2.2 and 2.3. It is important to mention here that the actual supplied water is found using pressure-dependent demand hydraulic analysis. At last, the fuzzy set approach is utilized to determine the $O D P I$. 


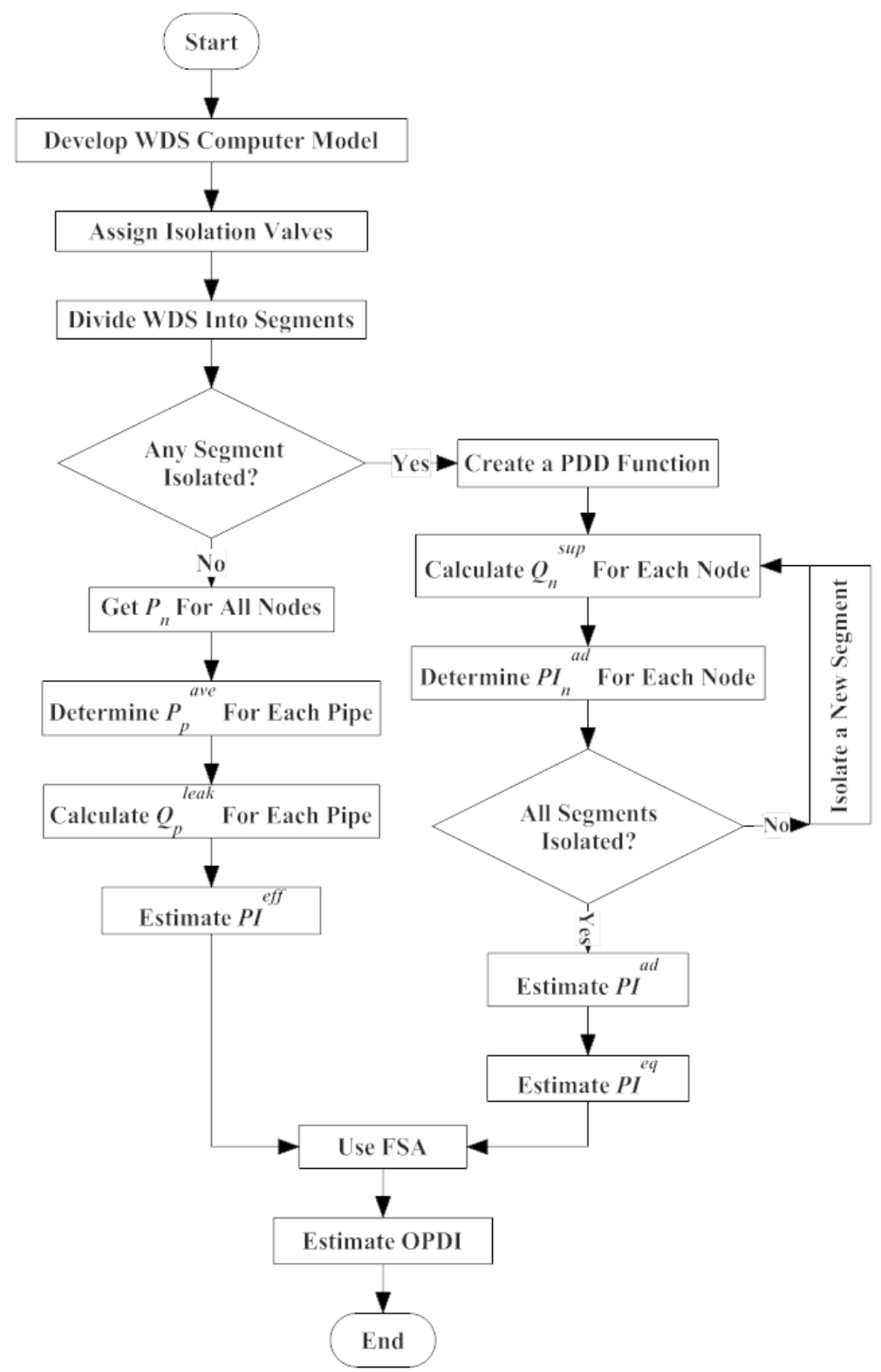

Fig. 5: Flowchart indicating the performance evaluation method.

\section{Application of the Proposed Methodology}

The proposed evaluation method is applied on 20 alternative designs of a hypothetical WDS. The various systems were designed by Tanyimboh and Templeman ,2000 [19], to achieve the required demands and $30 \mathrm{mH}_{2} \mathrm{O}$ minimum pressure at any node as shown in Figure 6. The alternative layouts and their diameters are illustrated in figure 7. The source pressure is $100 \mathrm{~m}$ at node 1 (source node). All pipes have the same length of 1000 meters. The used Hazen-Williams coefficient is 130. The locations of the isolation valves are added as shown in Figure 6. The valves are placed as specified in ECP-102 (2007) [20], such that one isolation valve is located at the end of each pipe with a diameter of less than $300 \mathrm{~mm}$. Otherwise, the valves are put at both the beginning and end of the water main while keeping the distance between valves limited to 500-1000 m. The hydraulic analysis was performed using WaterGEMS software because of its ability to simulate the system during pressure deficient conditions by applying the power function of pressure-dependent demand (PDD) analysis [21].Unlike demand-dependent analysis which is unable to compute the actual supplied water during pressure lack and gives illogic negative pressures, Pressure-dependent approach can determine the fraction of the nodal demand satisfied according to the available pressure. Here, pressure-demand relationships in this modelling are defined as a power function with standard power function exponent 0.5 . 


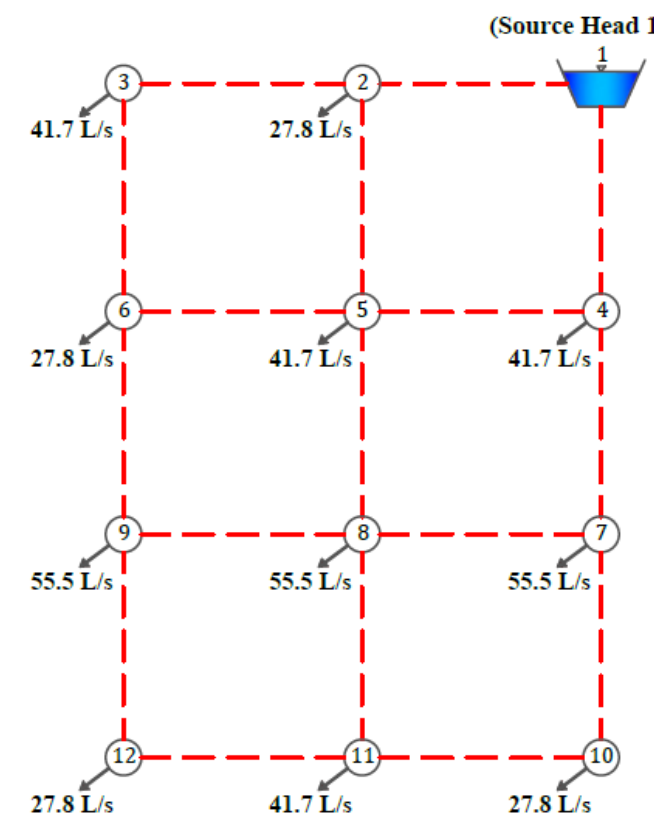

Fig. 6: Required demands at each node.
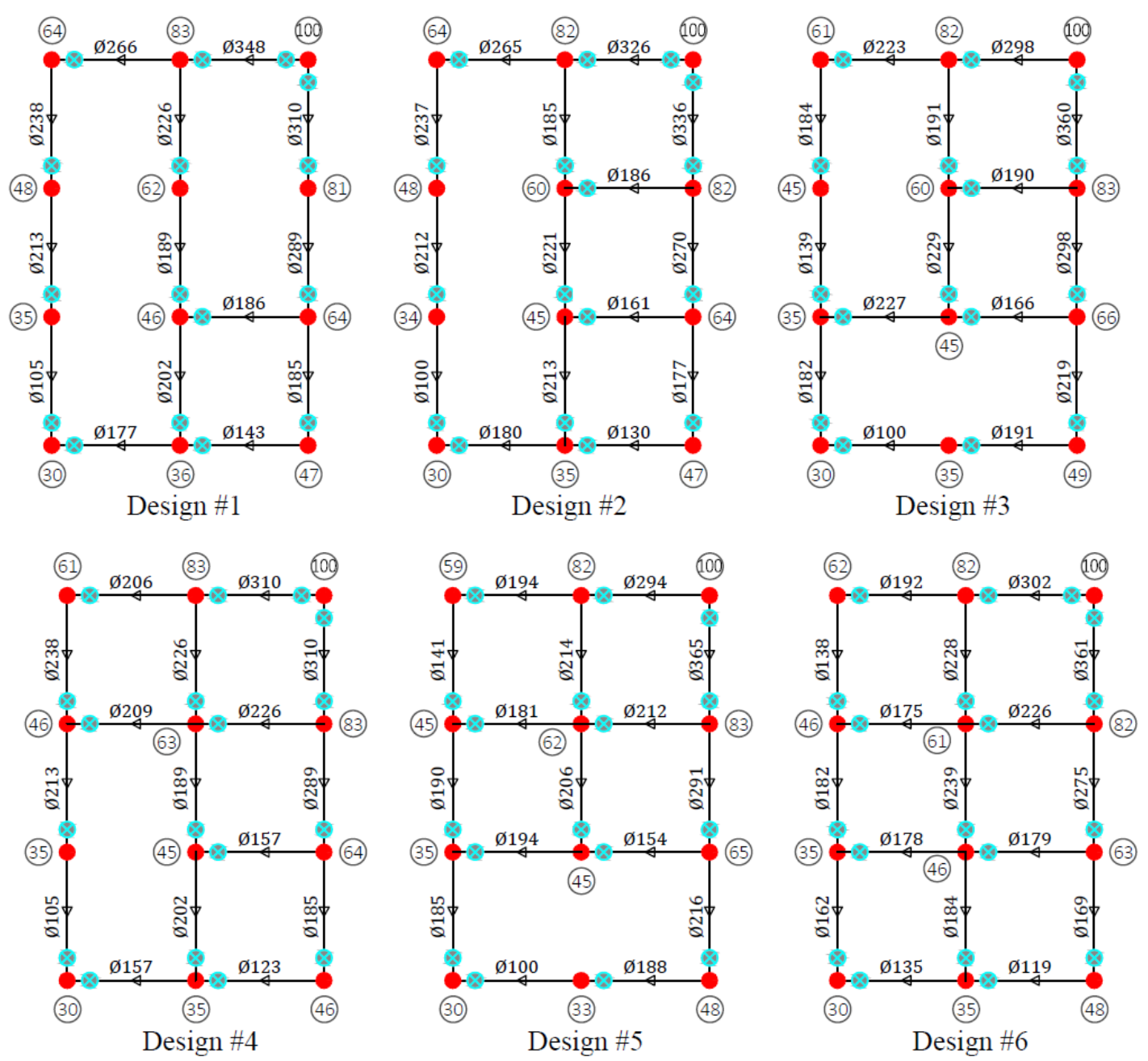

Fig. 7: The alternative designs of a WDS. 

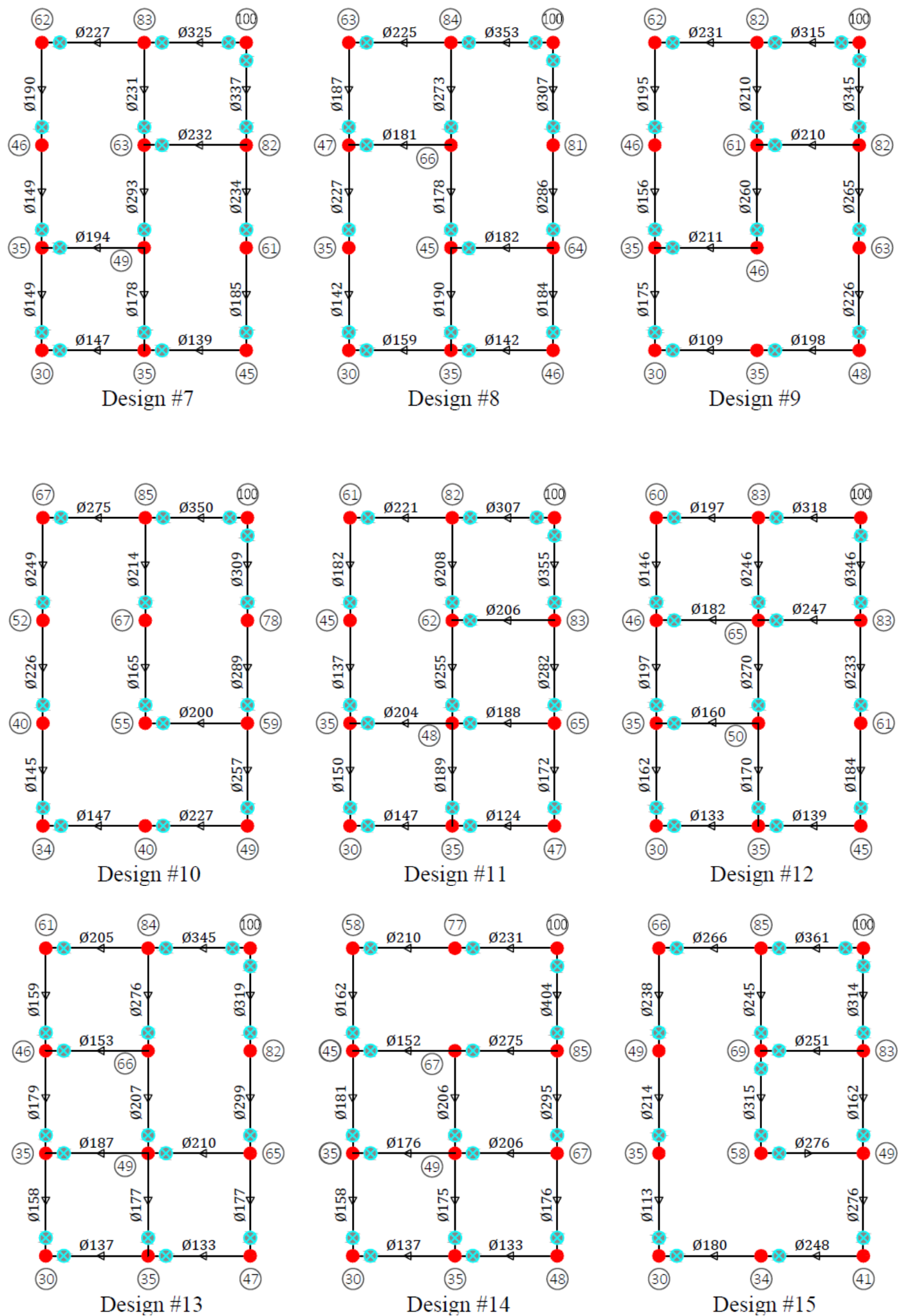

Fig: 7 Cont.: The alternative designs of a WDS. 

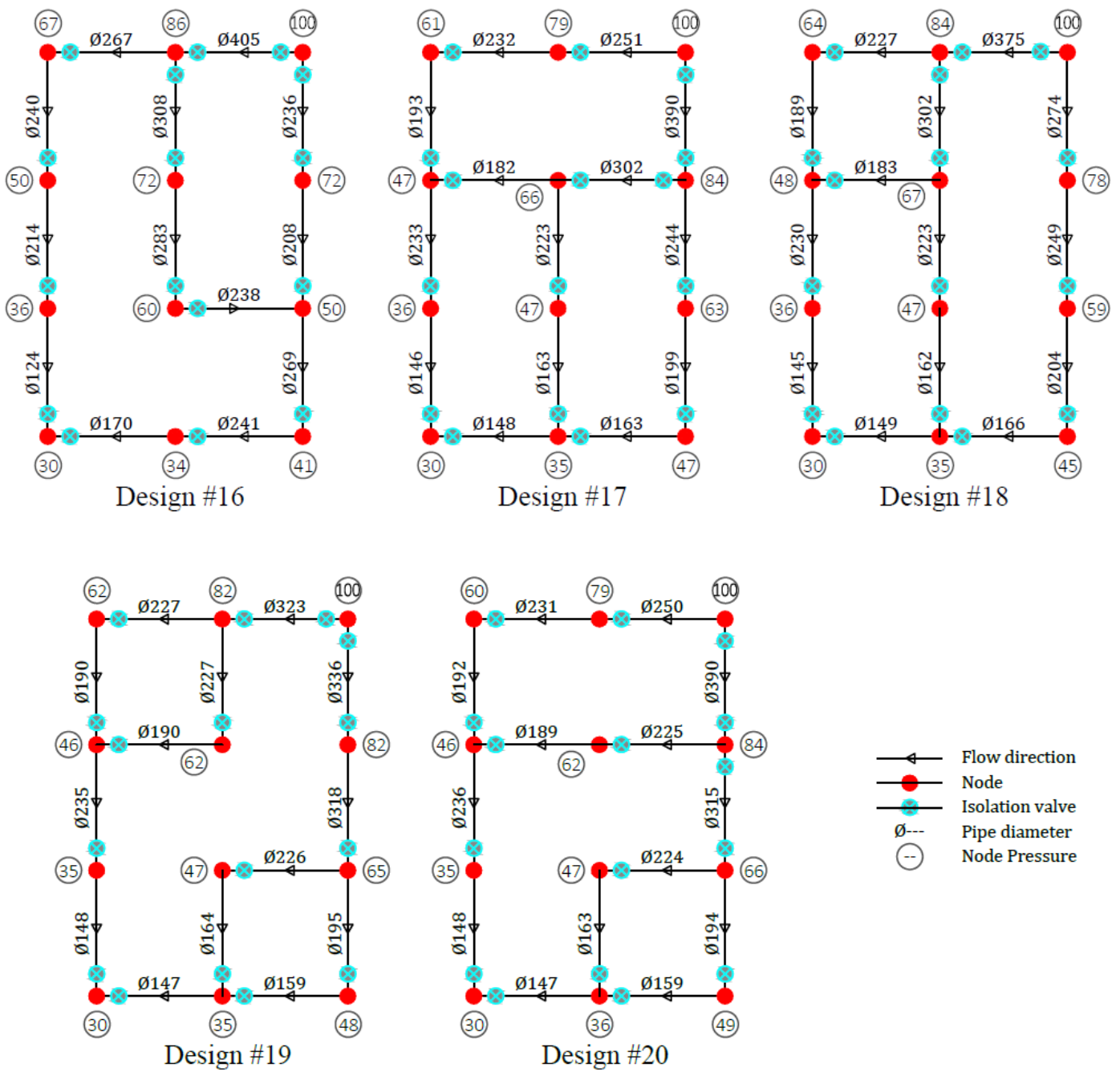

Fig.7: Cont.: The alternative designs of a WDS

\section{RESULTS AND DISCUSSION}

Applying equations 2, 3 and 5 to each of the 20 layouts, the response of the system regarding the three aspects i.e. efficiency, adequacy and equity is determined as indicated in table 1. By examining the values of the performance indices, it is found that no layout achieved the highest efficiency, adequacy and equity responses simultaneously. Using the values of indices in Table 1 and applying the fuzzy set approach, the Overall Design Performance Index is computed for each layout as depicted in Figure 8.

Table 1: Efficiency, adequacy, equity and cost for each design.

\begin{tabular}{|rcccr|rrrrr|}
\hline $\begin{array}{l}\text { Des. } \\
\text { No. }\end{array}$ & Efficiency & Adequacy & Equity & $\begin{array}{c}\text { Cost } \\
\left(*^{2} 10^{\wedge} 6\right)\end{array}$ & $\begin{array}{l}\text { Des. } \\
\text { No. }\end{array}$ & Efficiency & Adequacy & Equity & $\begin{array}{c}\text { Cost } \\
\left(*^{*} 10^{\wedge} 6\right)\end{array}$ \\
\hline 1 & 0.7232 & 0.7042 & 0.5010 & 1.189 & 11 & 0.6969 & 0.7299 & 0.5686 & 1.212 \\
2 & 0.7074 & 0.7172 & 0.5238 & 1.241 & 12 & 0.6963 & 0.7366 & 0.5869 & 1.253 \\
3 & 0.7069 & 0.6927 & 0.5019 & 1.22 & 13 & 0.6989 & 0.7095 & 0.5396 & 1.253 \\
4 & 0.6942 & 0.7320 & 0.5887 & 1.22 & 14 & 0.6996 & 0.6995 & 0.4872 & 1.247 \\
5 & 0.6957 & 0.7229 & 0.5360 & 1.253 & 15 & 0.7140 & 0.7061 & 0.5352 & 1.232 \\
6 & 0.6844 & 0.7384 & 0.5918 & 1.251 & 16 & 0.7336 & 0.6900 & 0.5004 & 1.41 \\
7 & 0.7101 & 0.7286 & 0.5746 & 1.281 & 17 & 0.7230 & 0.6983 & 0.5057 & 1.307 \\
8 & 0.709724 & 0.7091 & 0.5201 & 1.223 & 18 & 0.7233 & 0.6993 & 0.4904 & 1.184 \\
9 & 0.7204 & 0.7149 & 0.5285 & 1.224 & 19 & 0.7239 & 0.6823 & 0.4320 & 1.188 \\
10 & 0.7247 & 0.6952 & 0.4700 & 1.201 & 20 & 0.7233 & 0.6869 & 0.4612 & 1.192 \\
\hline
\end{tabular}




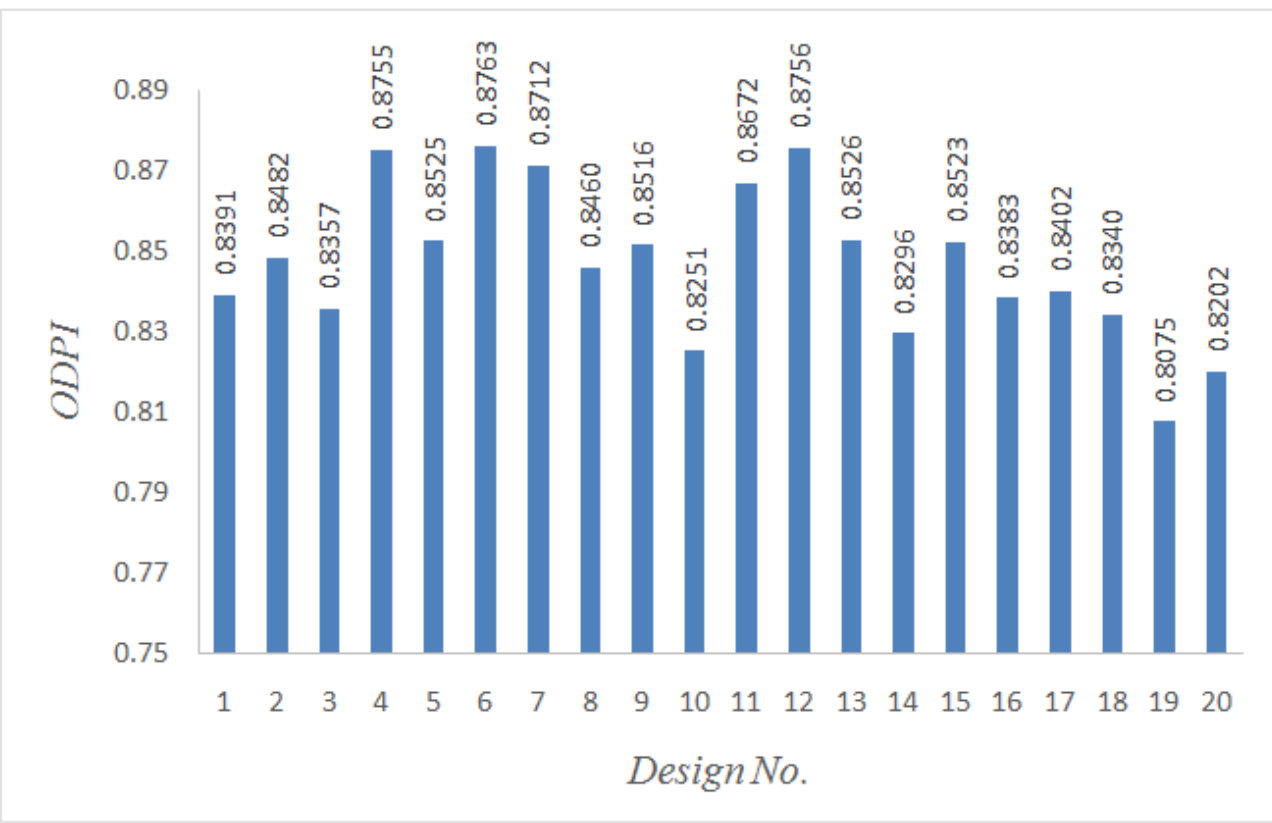

Fig. 8: $O P D I$.

In Figure 9, the relationship between the ODPI and each index is plotted using the values of all layouts. The graph depicts that $O D P I$ has strong positive correlation to adequacy and equity while it is inversely proportional to efficiency with weak correlation. Although Layout 6 has the highest relevance and investment, it has minimum efficiency. Also, table 1 shows that layout 16 has the best capability and lowest values of adequacy and equity. This indicates that designs with the maximum nodes' supply ratio would, on one side, distribute the water more uniformly among the end-user and, on the other side, would lead to a high amount of leaked water.

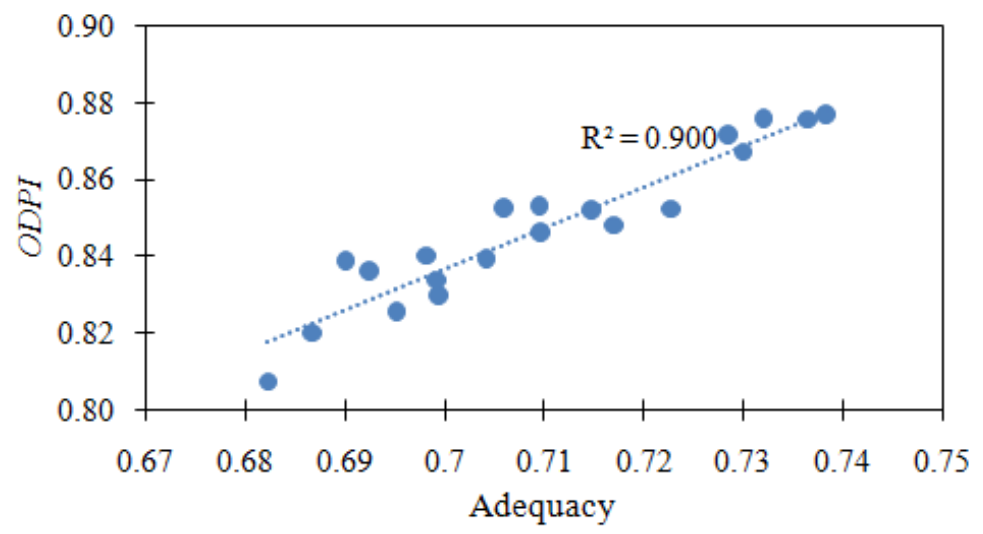

(a)

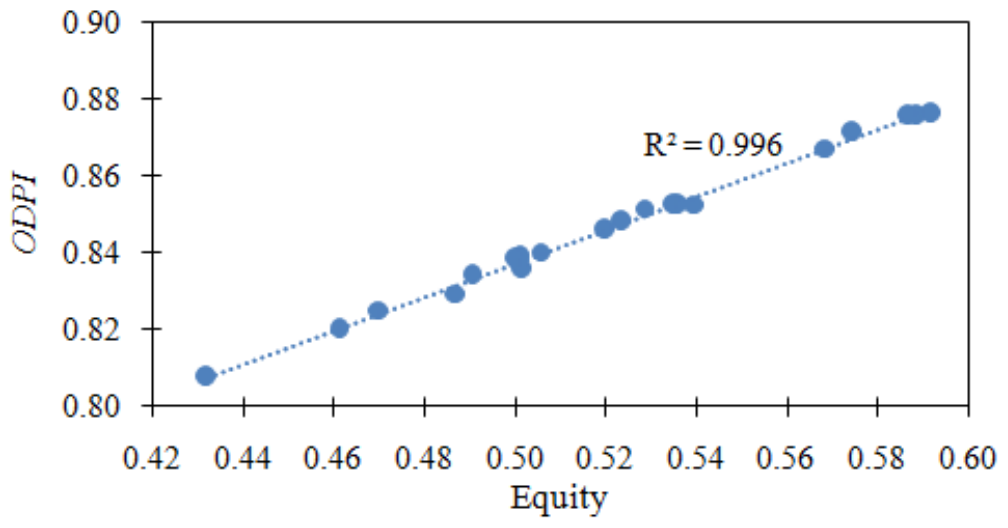

(b) 


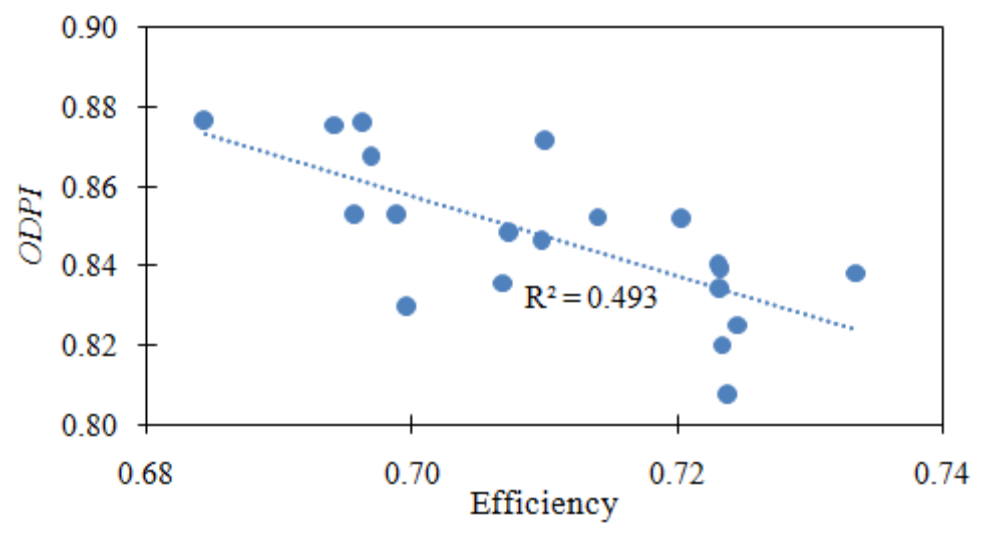

(c)

Fig.9: Relationship between $O P D I$ and (a) adequacy, (b) equity and (c) efficiency.

\section{Effect of Network Parameters on the Performance Indices}

Trying to better understand these relationships, the influence of some properties of the distribution system on the efficiency, adequacy and equity of water delivery is studied. Figure (10) indicates the effect of (a) number of paths in which the water moves through from the source to the end node, (b) sum of all these paths' length, and (c) number of pipes of the network on the three indices. It is obvious that these factors play a great role in controlling the performance of a system. Their increase enhances the adequacy and equity by helping in better distribution of water throughout the network. But in the same time, the more paths and pipes means more leakage problems and subsequently lower efficiency.

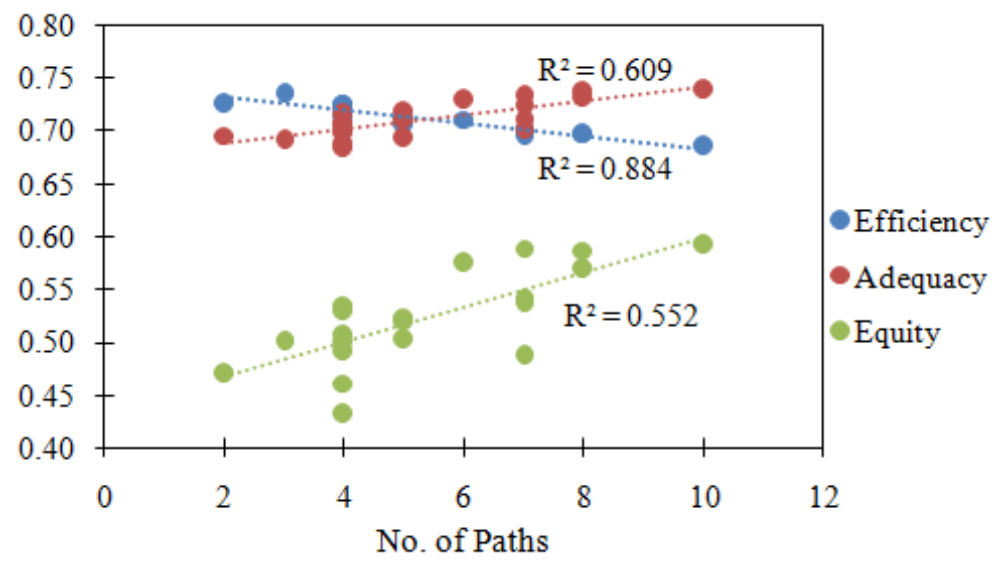

(a)

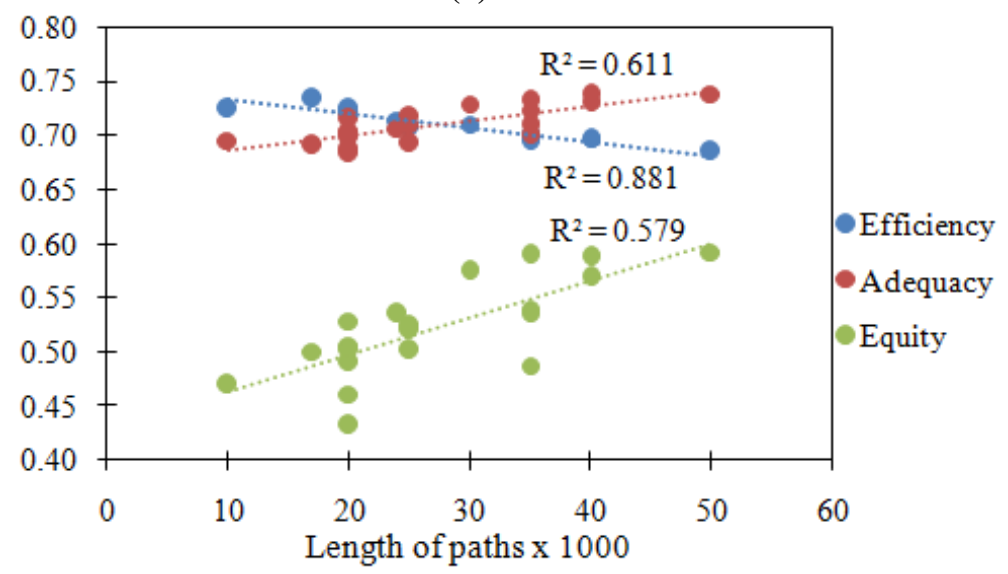

(b) 


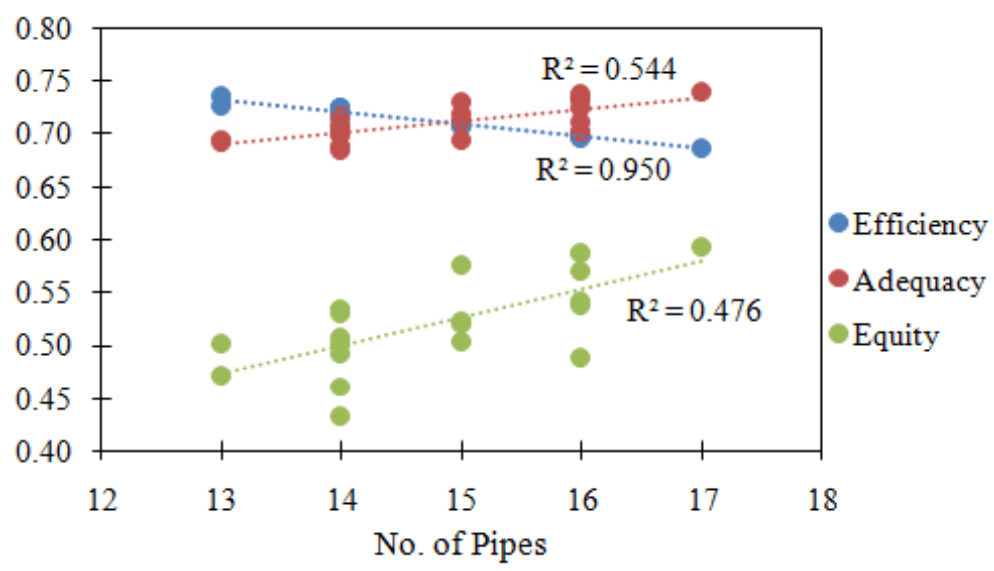

(c)

Fig.10: Effect of (a) No. of paths, (b) length of paths, and (c) No. of pipes on the three indices.

\section{Cost versus ODPI}

For a long time, people thought that increasing cost mean somehow a good distribution network, so contractors and consultants were on opposite sides. To find out the effect of cost on the ODPI, the cost of network is plotted against ODPI. Costs were taken from previous study by Tanyimboh and Templeman (2000) [19].

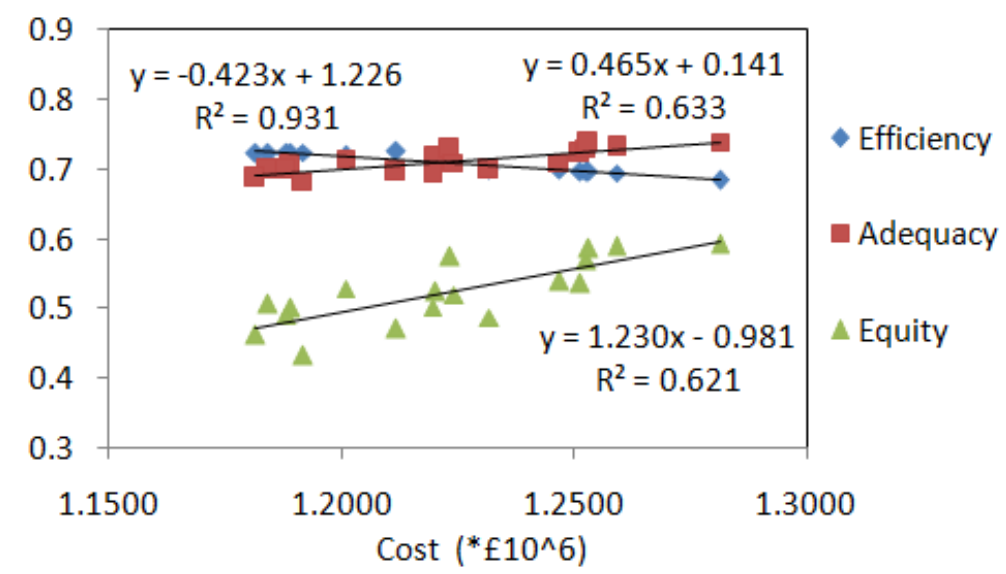

(a)

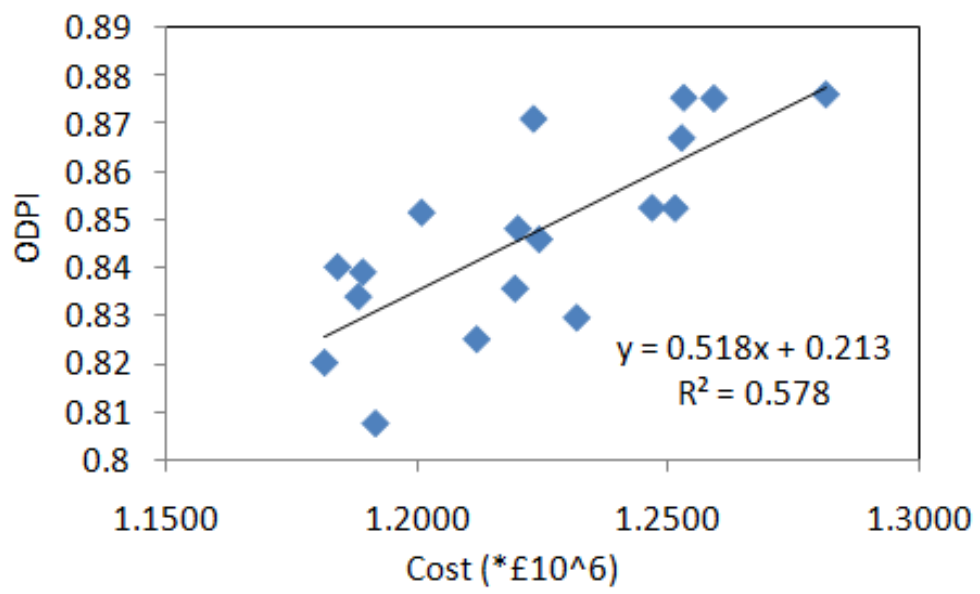

(b)

Fig.11: Cost versus (a) Efficiency, Adequacy and Equity. (b) ODPI.

Figure 11 shows a set of relationships that can be used in early design stages of the network. There is a strong inverse correlation between the cost and the Efficiency Performance Index -which agree with [22], while, show a moderate correlation between the cost and the Adequacy and Equity Performance Indices. These correlations indicate that increasing costs because of the increase in the number of pipes, diameters and paths leads to an increase in the possibility of leakage and on the other hand stability in network distribution against network failure. 
In this paper, a new method is proposed to evaluate the performance of water distribution systems. The method aims to find an Overall Design Performance Index (ODPI) which is a multi-aspect performance evaluation index ranges from 0 (the lowest performance) to 1 (the highest performance). The aspects considered were the efficiency of the system at normal operating conditions and its adequacy and equity at abnormal operating conditions. By applying the methodology on 20 alternative designs for a certain WDS while applying the pressure-dependent hydraulic analysis and the segment isolation technique, the following points are concluded:

- $O D P I$ directly proportional to the adequacy and equity aspects of a WDS with a strong coefficient of determination, $R^{2}$.

- There is an inverse proportion between the $O D P I$ and the efficiency index.

- Designs with the maximum adequacy would, distribute the water more uniformly among the end users and, on the other side, would lead to a high amount of water losses i.e. lowest efficiency.

- Increasing number of pipes, sum of paths' length, and number of available paths in a network would result in better adequacy and equity and worse efficiency.

- Sometimes it will be useful to use performance indices individually depending on the importance of this index for the design goals.

- There is not a well-defined relationship between the cost and ODPI. This is because the cost is mainly governed by the number and size of pipes. So, increasing the cost causes increase of adequacy and equity but lower efficiency and more water losses. However, this is not to say that cost does not affect the performance at all but is to say that is not the general case.

\section{REFERENCES}

[1] Swamee, P. K., \& Sharma, A. K. (2008). Design of water supply pipe networks. John Wiley \& Sons.

[2] Ataoui, R., \& Ermini, R. (2015). Overall performance of water distribution system: a methodology. Journal of Applied Water Engineering and Research,3(1), 19-28.

[3] Gheisi, A., \& Naser, G. (2015). Multi-aspect Performance Analysis of Water Distribution Systems under Pipe Failure. Procedia Engineering, 119, 158-167.

[4] Ghorbanian, V., Karney, B., \&Guo, Y. (2015). Minimum pressure criterion in water distribution systems: challenges and consequences. EWRI 2015: Floods, Droughts, and Ecosystems: Managing Our Resources Despite Growing Demands and Diminishing Funds.

[5] Jalal, M. M. (2009). Performance Measurement of Water Distribution Systems (WDS). A critical and constructive appraisal of the state-of-the-art (Doctoral dissertation).

[6] Walski, T. M. (1993). Water distribution valve topology for reliability analysis. Reliability engineering \& system safety, 42(1), 21-27.

[7] Bos, M. G., Burton, M. A. S., \&Molden, D. J. (2005). Irrigation and drainage performance assessment: practical guidelines. CABI.

[8] Jowitt, P. W., \& Xu, C. (1990). Optimal valve control in water-distribution networks. Journal of Water Resources Planning and Management, 116(4), 455-472.

[9] Twort, A. C., Hoather, R. C., \& Low, F. M. (1974). Water supply, 3nd Edi.Edward Arnold Ltd. Pub., London.

[10] Watergy (2009). http://www.watergy.net/-overview/ why.php. Acessed in: 09/28/2009.

[11] Germanopoulos, G. (1985). A technical note on the inclusion of pressure dependent demand and leakage terms in water supply network models. Civil Engineering Systems, 2(3), 171-179.

[12] Bertola, P., \& Nicolini, M. (2006, May). Evaluating reliability and efficiency of water distribution networks. In Centro Studi Sistemi Acquedottistici. Management of Water Networks, Proceeding of the Conference of the Efficient Management of Water Networks, Design and Rehabilitation Techniques, Ferrara (Italy).

[13] Shuang, Q., Zhang, M., \& Yuan, Y. (2014). Performance and reliability analysis of water distribution systems under cascading failures and the identification of crucial pipes. PloS one, 9(2), e88445.

[14] Gottipati, P. V., \& Nanduri, U. V. (2014). Equity in water supply in intermittent water distribution networks. Water and Environment Journal, 28(4), 509-515.

[15] Zimmermann, H. J. (1996). Fuzzy Control. In Fuzzy Set Theory-and Its Applications (pp. 203-240). Springer Netherlands.

[16] Lu, J., Zhang, G., Ruan, D., \& Wu, F. (2007). Multi-Objective Group Decision Making: Methods, Software and Applications with Fuzzy Set Techniques (With CD-ROM) (Vol. 6). World Scientific.

[17] Karwowski, W., \& Mital, A. (1986). Potential applications of fuzzy sets in industrial safety engineering. Fuzzy sets and systems, 19(2), 105-120.

[18] Kahraman, C., Demirel, N. Ç., Demirel, T., \&Ateş, N. Y. (2008). A SWOT-AHP application using fuzzy concept: EGovernment in Turkey. In Fuzzy Multi-Criteria Decision Making (pp. 85-117). Springer US.

[19] Tanyimboh, T. T., \& Templeman, A. B. (2000). A quantified assessment of the relationship between the reliability and entropy of water distribution systems. Engineering Optimization, 33(2), 179-199.

[20] Egyptian code practice (2007). Design and implementation of pipeline networks and sewage drinking water. (Code 102).

[21] Bentley Systems, 2006, WaterGEMS, Bentley Systems Incorporated, Exton, PA.

[22] Hanan A. F., Ahmed M. A., Wail A. F., Marwa A. D.. (2016).Correlation between Cost and Performance of Drinking Water Pipe Network during Normal Operating Conditions. International Journal of Research in Engineering and Technology.Volume: 05 Issue: 07. 